\title{
Interleukin-6 via Toll-Like Receptor 3 Signaling Attenuates the Expression of Proinflammatory Chemokines in Human Podocytes
}

\author{
Hidenori Umetsu ${ }^{a}$ Shojiro Watanabe ${ }^{a}$ Tadaatsu Imaizumi $^{b}$ Tomomi Aizawa ${ }^{a}$ \\ Koji Tsugawa $^{a}$ Shogo Kawaguchi $^{b}$ Kazuhiko Seya $^{b}$ Tomoh Matsumiya $^{b}$ \\ Hiroshi Tanaka a, c \\ aDepartment of Pediatrics, Hirosaki University Graduate School of Medicine, Hirosaki, Japan; bepartment of \\ Vascular Biology, Hirosaki University Graduate School of Medicine, Hirosaki, Japan; 'Department of School Health \\ Science, Hirosaki University Faculty of Education, Hirosaki, Japan
}

\begin{abstract}
Keywords
C-C motif chemokine ligand $5 \cdot$ Interleukin-6 $\cdot$ Monocyte chemoattractant protein-1 - Podocytes · Toll-like receptor 3
\end{abstract}

\begin{abstract}
Background: Although toll-like receptor 3 (TLR3) signaling is involved in the development of certain chronic kidney diseases, the specific molecular mechanisms underlying inflammatory reactions via activation of TLR3 signaling in human podocytes remain unclear. Interleukin (IL)- 6 is a pleiotropic cytokine associated with innate and adaptive immune responses; however, little is known about the implication of IL- 6 via the activation of regional TLR3 signaling in the inflammatory reactions in human podocytes. Methods: We treated immortalized human podocytes with polyinosinicpolycytidylic acid (poly IC), an authentic viral double-stranded RNA, and assessed the expression of IL-6, monocyte chemoattractant protein-1 (MCP-1), and C-C motif chemokine ligand 5 (CCL5) using quantitative real-time reverse transcription-polymerase chain reaction and enzyme-linked immunosorbent assay. To further elucidate the poly IC-induced signaling pathway, we subjected the cells to RNA interference against IFN- $\beta$ and IL-6. Results: We found that the acti-
\end{abstract}

vation of TLR3 induced expression of IL-6, MCP-1, CCL5, and IFN- $\beta$ in human podocytes. RNA interference experiments revealed that IFN- $\beta$ was involved in the poly IC-induced expression of IL-6, MCP-1, and CCL5. Interestingly, IL-6 knockdown markedly increased the poly IC-induced expression of MCP-1 and CCL5. Further, treatment of cells with IL-6 attenuated the expression of CCL5 and MCP-1 mRNA and proteins. Conclusion: IL- 6 induced by TLR3 signaling negatively regulates the expression of representative TLR3 signaling-dependent proinflammatory chemokines in human podocytes.

¿ 2021 The Author(s).
Published by S. Karger AG, Basel

\section{Introduction}

In clinical practice, viral infections are known to trigger the development of chronic kidney diseases (CKD) or worsen the pre-existing CKD $[1,2]$. Recognition of the molecular pattern of viral pathogens by toll-like receptor 3 (TLR3) found in intracellular endosomes and subsequent immunoreactions is important in host antiviral defenses [3]. TLR3 signaling cascades activate the toll/interleukin (IL)-1 receptor-domain-containing adapter-inducing interferon- $\beta$-dependent pathways and the karger@karger.com www.karger.com/kbr

Karger $\stackrel{\text { ' }}{=}$

BOPEN ACCESS
(C) 2021 The Author(s)

Published by S. Karger AG, Basel

This is an Open Access article licensed under the Creative Commons Attribution-NonCommercial-4.0 International License (CC BY-NC) (http://www.karger.com/Services/OpenAccessLicense), applicable to the online version of the article only. Usage and distribution for commercial purposes requires written permission.
Correspondence to:

Hiroshi Tanaka, hirotana@hirosaki-u.ac.jp 
subsequent release of inflammatory chemokines, cytokines, adhesion molecules, and eventually type I interferons [3]. Since the expression of TLR3 in resident glomerular cells is confirmed in biopsy specimens from patients with CKD $[4,5]$, regional antiviral host defenses via the activation of TLR3 signaling in the intrinsic glomerular cells have been postulated to be involved in the pathogenesis of some CKD types [4-6]. To date, considering the implications of TLR3 signaling in the pathogenesis of $\mathrm{CKD}$, we treated cultured human mesangial cells (MCs) and glomerular endothelial cells (GECs) with polyinosinic-polycytidylic acid (poly IC), an authentic viral doublestranded RNA, and thereafter examined the expressions of representative proinflammatory chemokines and cytokines [6-12]. Notably, podocytes themselves also reportedly express TLR3 and its downstream signaling pathways, and these axes are presumed to be involved in the pathogenesis of certain CKD forms [13, 14].

Among the TLR3 signaling-induced functional molecules in resident glomerular cells, we recently reported that TLR3 signaling can induce IL- 6 expression in GECs [11]. IL-6, a representative proinflammatory mediator, is known as a pleiotropic cytokine that regulates pro- and anti-inflammatory reactions in numerous cell types, including resident glomerular cells [15-17]. Considering the role of IL- 6 in podocytes, it has been reported that high glucose exposure-induced IL-6 expression causes apoptosis in rat podocytes [18]. In contrast, IL-6-dependent cellular crosstalk between podocytes and GECs may modulate glomerular inflammation by reduced recruitment of neutrophils to the endothelium [19]. Thus, IL-6 may play a pivotal role in inflammation as well as prove to be protective or deleterious in the pathogenesis of CKD $[17,19]$; however, the implication of IL- 6 expression via TLR3 signaling in human podocytes remains unclear. Therefore, in the present study, we treated human podocytes with poly IC and evaluated the expression of IL- 6 in this cell type.

\section{Materials and Methods}

\section{Reagents}

Insulin-transferrin-selenium-A supplement, penicillin-streptomycin, and siRNA against TLR3 (4427038) were purchased from Thermo Fisher Scientific (Asheville, MA, USA). RPMI-1640 and poly IC as a TLR3 ligand were obtained from Sigma (St. Louis, MO, USA). Small-interfering RNAs (siRNAs) against IL-6 (1299001) were purchased from Invitrogen (Frederick, MD, USA). A nonsilencing negative control siRNA (1027281) was purchased from Qiagen (Hilden, Germany). Lipofectamine RNAiMAX was supplied by Invitrogen (Carlsbad, CA, USA). An illustra RNA spin kit
Table 1. Oligonucleotide primers used for quantitative real-time PCR

\begin{tabular}{|c|c|}
\hline cDNA & Primers \\
\hline \multirow[t]{2}{*}{ IL-6 } & F: 5'-ATGAACTCCTTCTCCACAAGC-3' \\
\hline & R: 5'-AAGAGCCCTCAGGCTGGACTG-3' \\
\hline \multirow[t]{2}{*}{ CCL5 } & F: $5^{\prime}$-CTACTCGGGAGGCTAAGGCAGGAA-3' \\
\hline & R: 5'-GAGGGGTTGATACGGCGGAAGC-3' \\
\hline \multirow[t]{2}{*}{ MCP-1 } & F: 5'-AAACTGAAGCTCGCACTCGC-3' \\
\hline & R: 5'-ATTCTTGGGTTGTTGAGTGAGT-3' \\
\hline \multirow[t]{2}{*}{ IFN- $\beta$} & F: 5'-CCTGTGGCAATTGAATGGGAGGC-3' \\
\hline & R: 5'-CCAGGCACAGTGACTGTACTCCTT-3' \\
\hline \multirow[t]{2}{*}{ TLR3 } & F: $5^{\prime}$-CTCAGAAGATTACCAGCCGCC-3' \\
\hline & R: 5'-CCATTATGAGACAGATCTAATG-3' \\
\hline \multirow[t]{2}{*}{ GAPDH } & F: 5'-GCACCGTCAAGGCTGAGAAC-3' \\
\hline & R: 5'-ATGGTGGTGAAGACGCCAGT-3' \\
\hline
\end{tabular}

IL-6, interleukin-6; CCL5, chemokine ligand 5; MCP-1, monocyte chemoattractant protein- 1 ; IFN- $\beta$, interferon- $\beta$; TLR3, toll-like receptor 3; GAPDH, glyceraldehyde-3-phosphate dehydrogenase.

was obtained from GE Healthcare (Buckinghamshire, UK). Oligo $(\mathrm{dT})_{18}$ primer and additional oligonucleotide primers for polymerase chain reaction (PCR) were custom synthesized by Greiner (Atsugi, Japan). Sso-Advanced Universal SYBR Green Supermix was obtained from Bio-Rad (Hercules, CA, USA). Moloney murine leukemia virus (MMLV) reverse transcriptase was obtained from Invitrogen. Recombinant human (r[h]) IL-6 and enzyme-linked immunosorbent assay (ELISA) kits for IL-6, C-C motif chemokine ligand 5 (CCL5), and monocyte chemoattractant protein-1 (MCP1) were supplied by R\&D Systems (Minneapolis, MN, USA). ELISA kits for IFN- $\alpha$ and IFN- $\beta$ were purchased from PBL Assay Science (Piscataway, NJ, USA). siRNA against IFN- $\beta$ is previously described [7-12]. Primer sequences are listed in Table 1.

\section{Cell Culture}

Immortalized human podocytes were kindly provided by Prof. Moin Saleem, the University of Bristol, UK. Cells were cultured in RPMI-1640 containing 10\% FBS, 1\% insulin-transferrin-selenium-A supplement, and penicillin-streptomycin $(100 \mathrm{U} / \mathrm{mL}$ and $100 \mu \mathrm{g} / \mathrm{mL}$, respectively). Cells were incubated at $33^{\circ} \mathrm{C}$ for proliferation under a humidified atmosphere of $95 \%$ air and $5 \% \mathrm{CO}_{2}$ and then thermoswitched from 33 to $37^{\circ} \mathrm{C}$ for differentiation under nonpermissive conditions for 14 days. Medium was changed 3 times a week. Differentiated cells were incubated in 1\% FBS for $24 \mathrm{~h}$ and then treated with poly IC. Poly IC was dissolved in phosphate-buffered saline, $\mathrm{pH} 7.4$, and the cells were treated with 10-50 $\mu \mathrm{g} / \mathrm{mL}$ poly IC for up to $24 \mathrm{~h}$.

In RNA interference experiments, cells were transfected in the 6-well plates with 20 pmol of siRNA (against TLR3, IFN- $\beta$, IL-6, or nonsilencing negative control siRNA) per well, using the Lipofectamine RNAiMAX reagent according to the supplier's protocol. The cells were $80-90 \%$ confluent at the time of transfection. After 48-h incubation, the cells were treated with poly IC as indicated. $\mathrm{r}$ (h) IL- 6 was added to cells at $40 \mathrm{ng} / \mathrm{mL}$, and cells were stimulated with $30 \mu \mathrm{g} / \mathrm{mL}$ poly IC. 


\section{A. qRT-PCR}
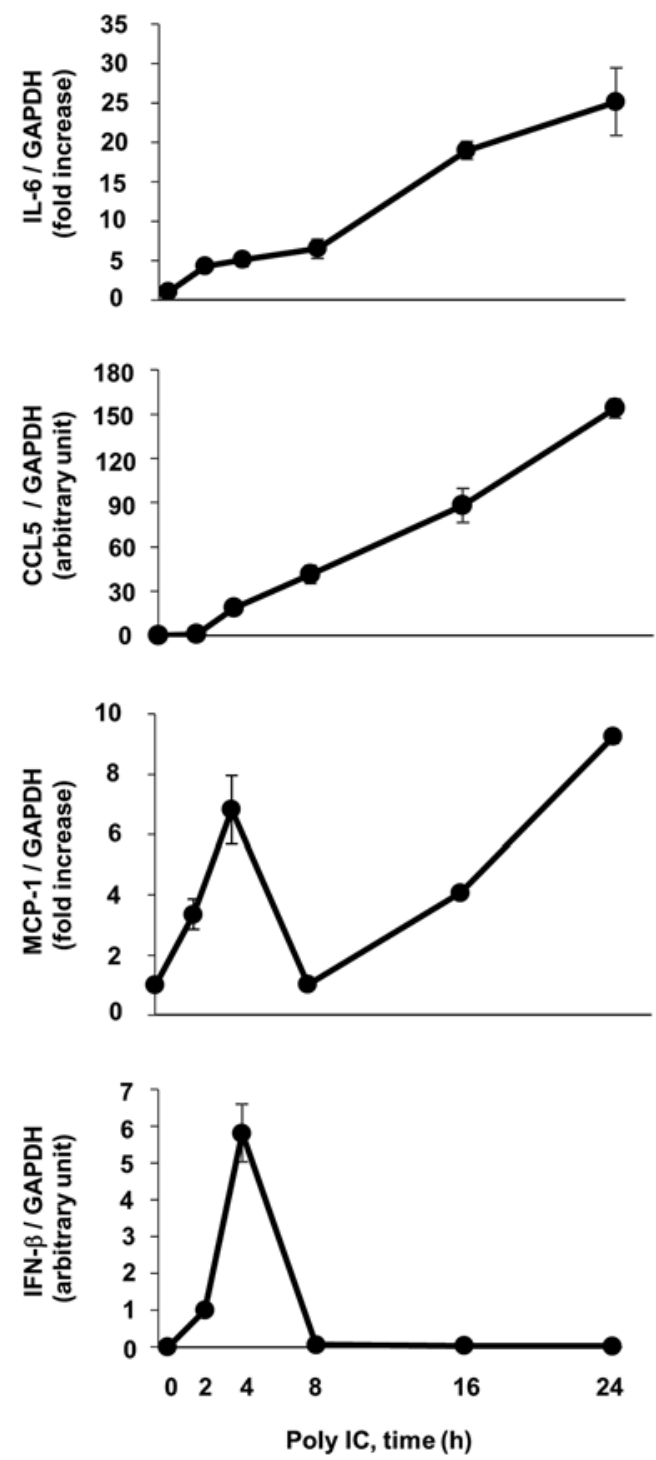

B. ELISA
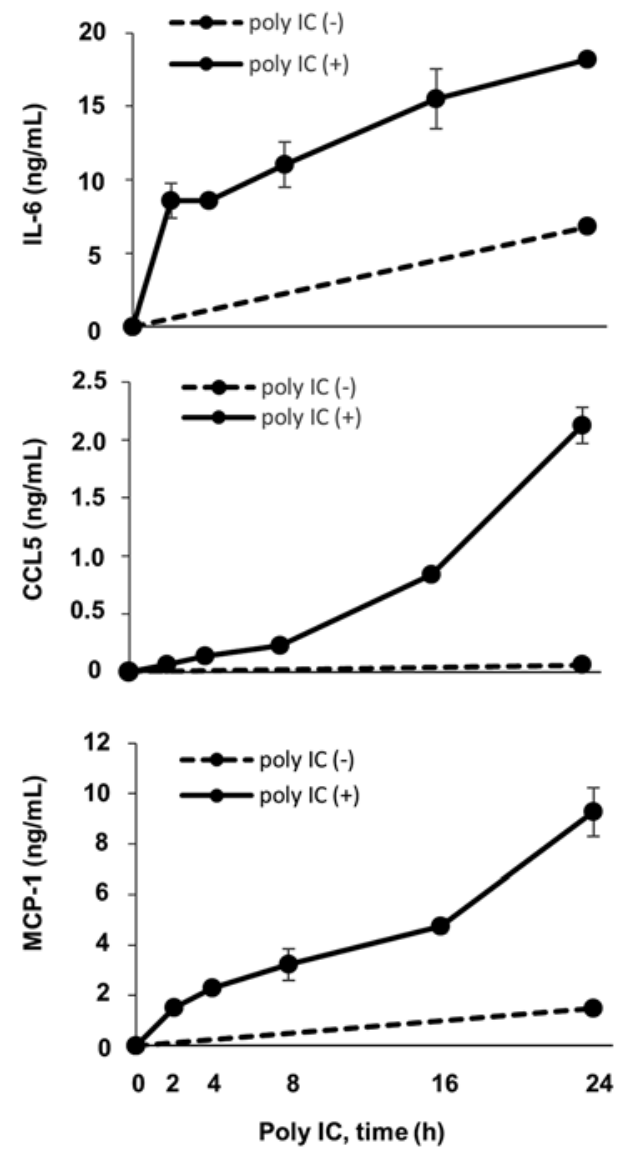

C. ELISA

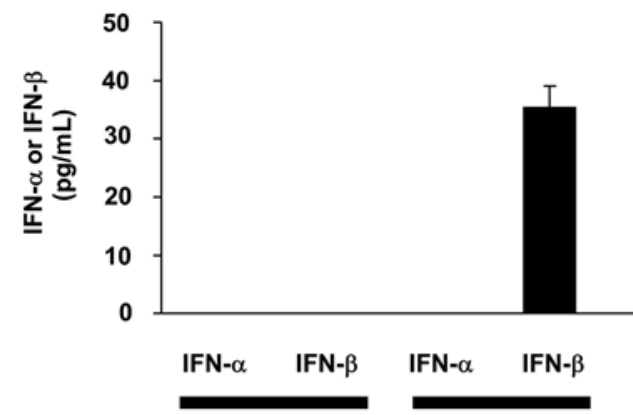

Poly IC :

$(-)$

$(+)$
Fig. 1. Poly IC induces the expression of IL-6, CCL5, MCP-1, and IFN- $\beta$ in cultured human podocytes in a time-dependent manner. Podocytes were cultured and treated with $30 \mu \mathrm{g} / \mathrm{mL}$ poly IC up to $24 \mathrm{~h}$. After 24-h incubation, RNA was extracted from the cells. A cDNA was synthesized, and the expression of IL-6, CCL5, MCP1 , and IFN- $\beta$ mRNA was estimated using qRT-PCR analysis. After 24 -h incubation, the conditioned medium was collected, and the

IL-6 and TLR3 Signaling in Human Podocytes cells were lysed. B The concentration of IL-6, CCL5, and MCP-1 protein in the collected medium was measured using ELISA kits. C IFN-a protein was not detected by ELISA at the time point of after 24 -h poly IC stimulation. The data are presented as means \pm standard deviation $(n=3)$. Poly IC, polyinosinic-polycytidylic acid; IL-6, interleukin-6; CCL5, chemokine ligand 5; MCP-1, monocyte chemoattractant protein-1; IFN- $\beta$, interferon- $\beta$. 


\section{A. $q R T-P C R$}
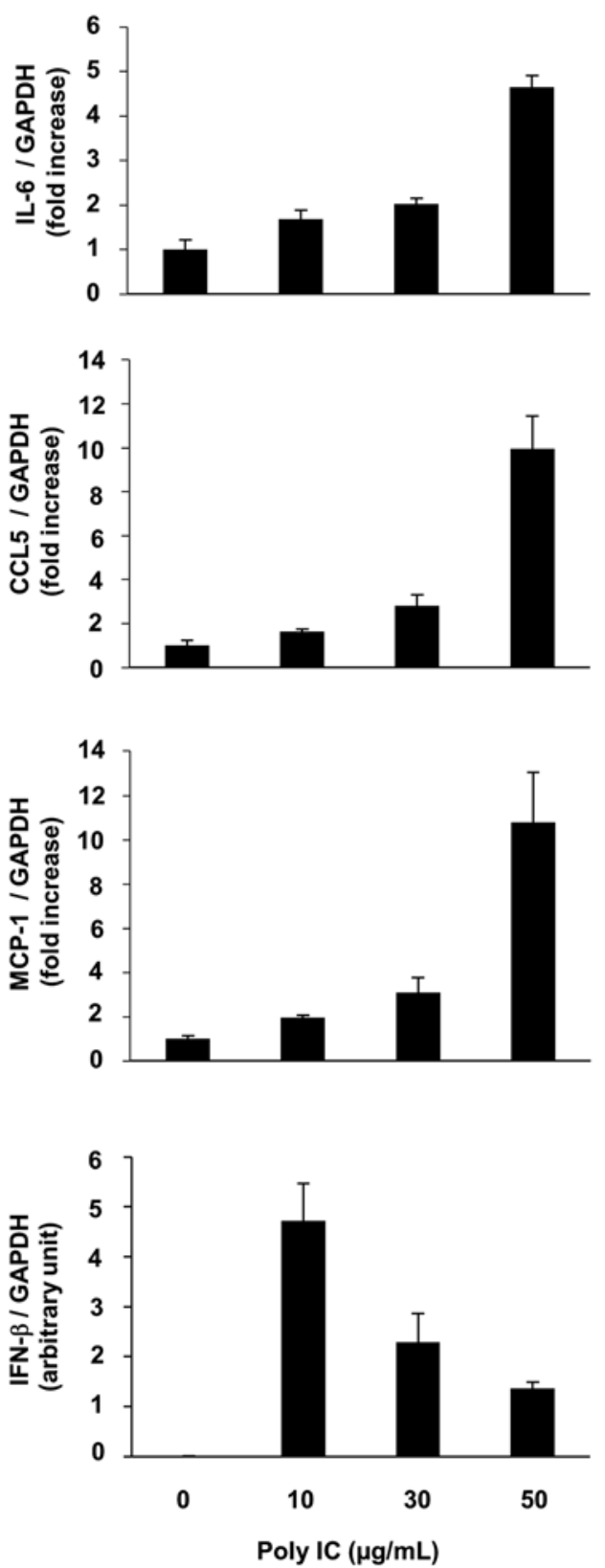

B. ELISA
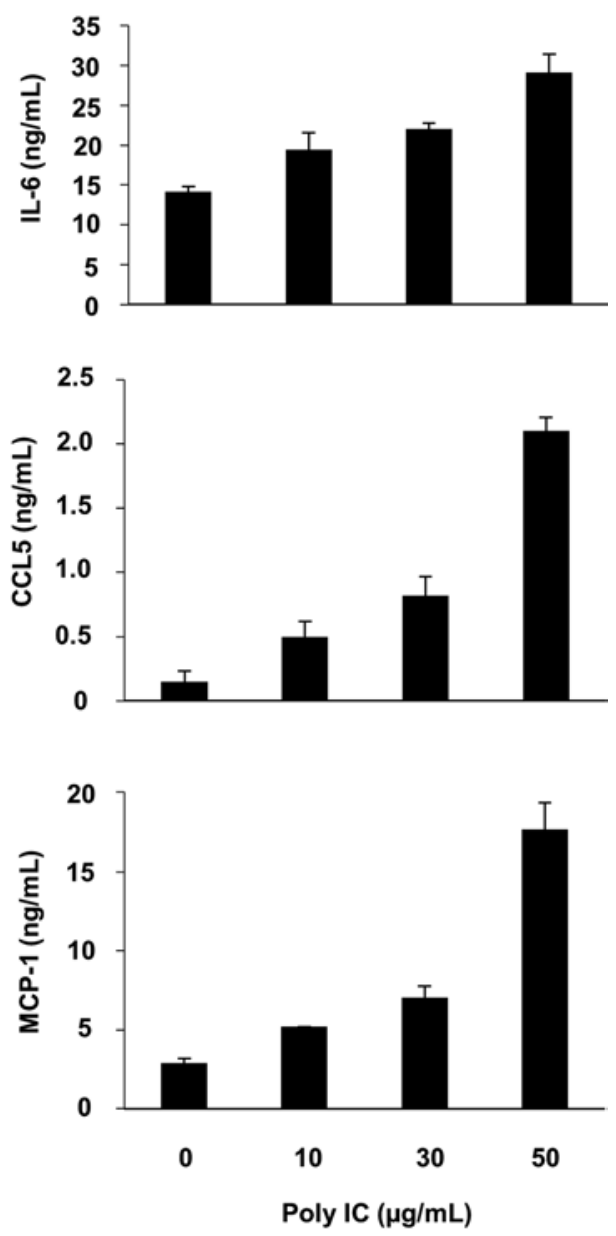

Fig. 2. Poly IC induces the expression of IL-6, CCL5, MCP-1, and IFN- $\beta$ in cultured human podocytes in a concentration-dependent manner. Podocytes were cultured and treated with $10-50 \mu \mathrm{g} / \mathrm{mL}$ poly IC for up to $24 \mathrm{~h}$. A The expressions of IL-6, CCL5, MCP-1, and IFN- $\beta$ mRNA were examined by qRT-PCR. B The concentra- tion of IL-6, CCL5, MCP-1, and IFN- $\beta$ proteins was estimated by ELISA. The data are presented as means \pm SD $(n=3)$. Poly IC, polyinosinic-polycytidylic acid; IL-6, interleukin-6; CCL5, chemokine ligand 5; MCP-1, monocyte chemoattractant protein-1; IFN- $\beta$, interferon- $\beta$. 


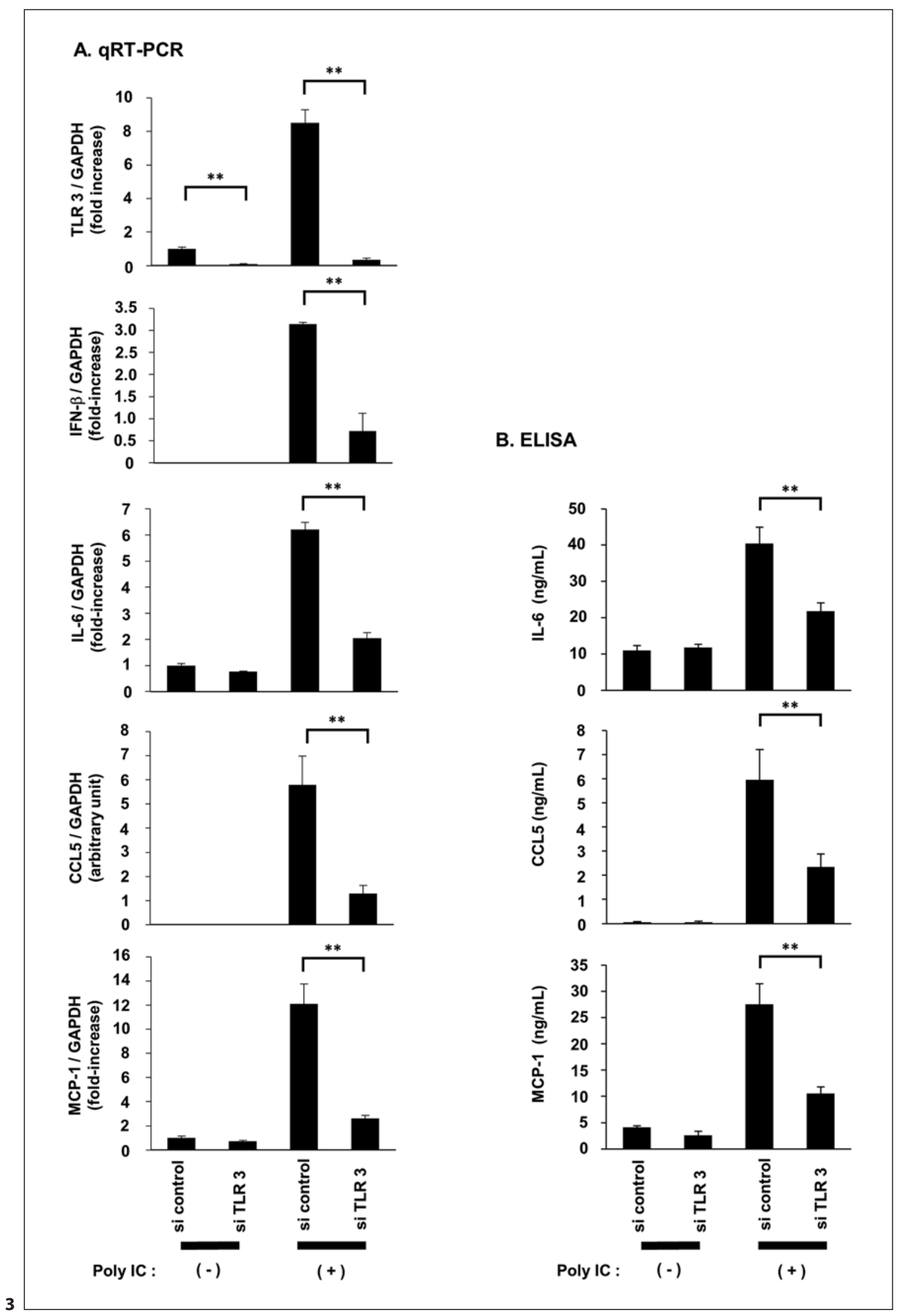

(For legend see next page.) 
Quantitative Real-Time Reverse Transcription PCR Analyses

Total cellular RNA was extracted from the cells using an illustra RNAspin kit. Single-stranded cDNA was synthesized from $1 \mu \mathrm{g}$ of total RNA using oligo $(\mathrm{dT})_{18}$ primer and MMLV reverse transcriptase. The cDNA for IL-6, CCL5, MCP-1, IFN- $\beta$, TLR3, or glyceraldehyde-3-phosphate dehydrogenase (GAPDH) was amplified using Sso-Advanced Universal SYBR Green Supermix. Data were analyzed and expressed in comparison with GAPDH. The sequences of the primers used are shown.

\section{ELISA}

The concentrations of IL- 6 , CCL5, MCP-1, IFN- $\alpha$, or IFN- $\beta$ protein in the cell-conditioned medium were measured using the ELISA kits according to the manufacturer's protocol.

\section{Statistical Analysis}

All experiments were performed at least 3 times. That was, 3 independent experiments, and each experiment was done with 3 samples per group. Values are reported as means \pm standard deviation. Differences between groups were analyzed using Student's $t$ test. A $p$ value $<0.05$ was considered as statistically significant. All analyses were carried out using GraphPad Prism software version 7 (GraphPad Software, Inc., La Jolla, CA, USA).

\section{Results}

Poly IC Induces the Expression of IL-6, CCL, MCP-1, and IFN- $\beta$ in Cultured Human Podocytes

Treatment of cultured human podocytes with poly IC induced the expression of IL- 6 , CCL5, MCP- 1 , and IFN- $\beta$ in a concentration-dependent manner (Fig. 1). The expression of GAPDH was not influenced by poly IC. IL-6 and CCL5 mRNA expression gradually increased up to 24 $\mathrm{h}$ after poly IC stimulation. MCP- 1 and IFN- $\beta$ mRNA expression rapidly increased after poly IC stimulation, peaked at $4 \mathrm{~h}$, and decreased and returning to the basal level at $8 \mathrm{~h}$, after which only MCP-1 mRNA increased again up to $24 \mathrm{~h}$ (Fig. 1A). IL-6, CCL5, and MCP-1 pro-

Fig. 3. Knockdown of TLR3 diminishes the poly IC-induced expression of IFN- $\beta$, IL-6, CCL5, and MCP-1 in cultured human podocytes. The cells were transfected with siRNA against TLR3 or a nonsilencing negative control siRNA and were incubated for 48 h. Then, the cells were stimulated with $30 \mu \mathrm{g} / \mathrm{mL}$ poly IC. RNA was extracted from the cells after $4 \mathrm{~h}$ of incubation for the analysis of IFN- $\beta$ or 24 h of incubation for the analysis of TLR3, IL-6, CCL5,

Fig. 4. IFN- $\beta$ is involved in poly IC-induced expression of IL-6, CCL5, and MCP-1 in cultured human podocytes. Cells were transfected with siRNA against IFN- $\beta$ or a nonsilencing negative control siRNA. After 48-h incubation, the cells were stimulated with $10 \mu \mathrm{g} / \mathrm{mL}$ poly IC for up to $24 \mathrm{~h}$. A To confirm the efficacy of siRNA against IFN- $\beta$, the expression of IFN- $\beta$ protein was measured by tein accumulated in the conditioned medium for up to $24 \mathrm{~h}$ in a time-dependent manner (Fig. 1B). IFN- $\alpha$ protein was not detected by ELISA at the time point of after 24 -h poly IC stimulation (Fig. 1C).

Poly IC also induced the expression of IL-6, CCL5, MCP-1, and IFN- $\beta$ in a concentration-dependent manner (Fig. 2). After poly IC stimulation, podocytes released higher levels of IL-6, CCL5, MCP-1, and IFN- $\beta$ compared to the unstimulated cultures. When the cells were treated with various concentration of poly IC $(10-50 \mu \mathrm{g} / \mathrm{mL})$, the expression of IL-6, CCL5, and MCP-1 mRNA (Fig. 1A) and protein (Fig. 1B) was induced in a concentration-dependent manner. The expression of IFN- $\beta$ mRNA peaked with $10 \mu \mathrm{g} / \mathrm{mL}$ poly IC stimulation (Fig. $2 \mathrm{~A}$ ).

\section{TLR3 Is Involved in IFN- $\beta, I L-6, C C L 5$, and MCP-1 Induction by Poly IC}

RNA interference against TLR3 significantly inhibited the expression of mRNAs for IFN- $\beta$, IL- 6 , CCL5, and MCP-1 (Fig. 3A). We confirmed that protein expression of IL-6, CCL5, and MCP-1 was decreased by RNA interference against TLR3 (Fig. 3B). Effective knockdown of TLR3 mRNA by RNA interference was confirmed by qRT-PCR (Fig. 3A).

\section{IFN- $\beta$ Involvement in the Poly IC-Induced Expression}

of IL-6, CCL5, and MCP-1

To evaluate the role of IFN- $\beta$ in poly IC-induced IL- 6 , CCL5, and MCP-1 expressions, we next performed the RNA interference experiments to knockdown the expression of IFN- $\beta$. Cell viability was evaluated using the trypan blue exclusion method. The viability of cells was $>90 \%$ even after the transfection of cells with siRNAs. Effective knockdown of IFN- $\beta$ expression was confirmed by ELISA (Fig. 4A). Knockdown of IFN- $\beta$ significantly in-

and MCP-1. A The expressions of TLR3, IFN- $\beta$, IL-6, CCL5, and MCP-1 mRNAs were examined by qRT-PCR analysis. B The concentration of IL-6, CCL5, and MCP-1 proteins was estimated by ELISA analysis. The data are means $\pm \mathrm{SD}\left(n=3,{ }^{* *} p<0.01\right)$. TLR3, toll-like receptor 3; poly IC, polyinosinic-polycytidylic acid; IL-6, interleukin-6; CCL5, chemokine ligand 5; MCP-1, monocyte chemoattractant protein- 1 ; IFN- $\beta$, interferon- $\beta$.

ELISA. The mRNA (B) and protein (C) expressions of IL-6, CCL5, and MCP-1 were examined as in Figure 2. The data are presented as means $\pm \mathrm{SD}\left(n=3,{ }^{*} p<0.05,{ }^{* *} p<0.01\right)$. IL-6, interleukin-6; CCL5, chemokine ligand 5; MCP-1, monocyte chemoattractant protein- 1 ; IFN- $\beta$, interferon- $\beta$.

(For figure see next page.) 
A. ELISA

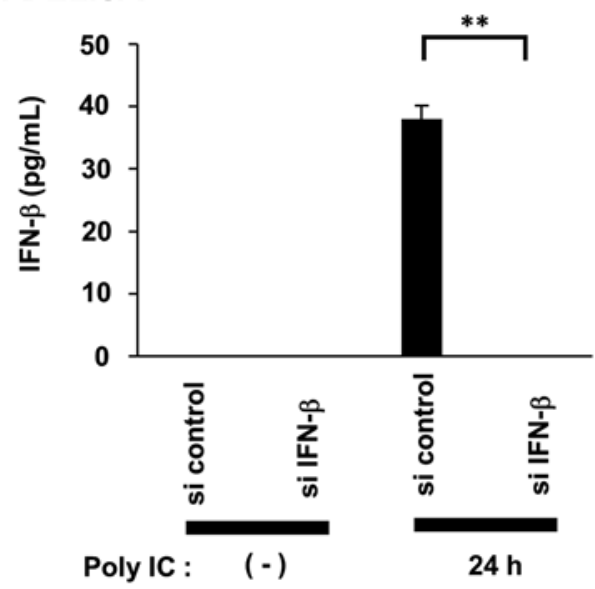

B. $q R T-P C R$

C. ELISA
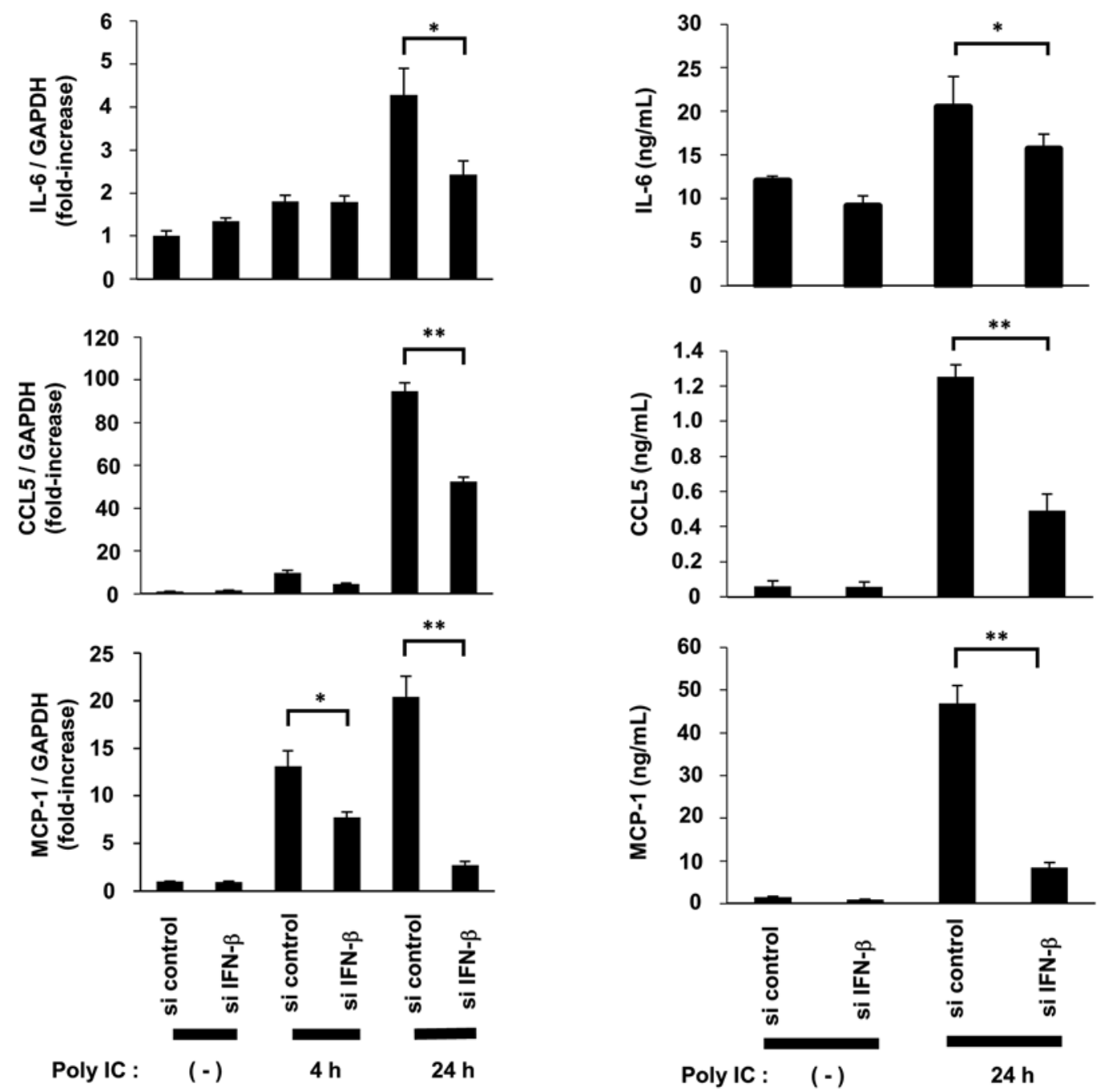


\section{A. qRT-PCR}
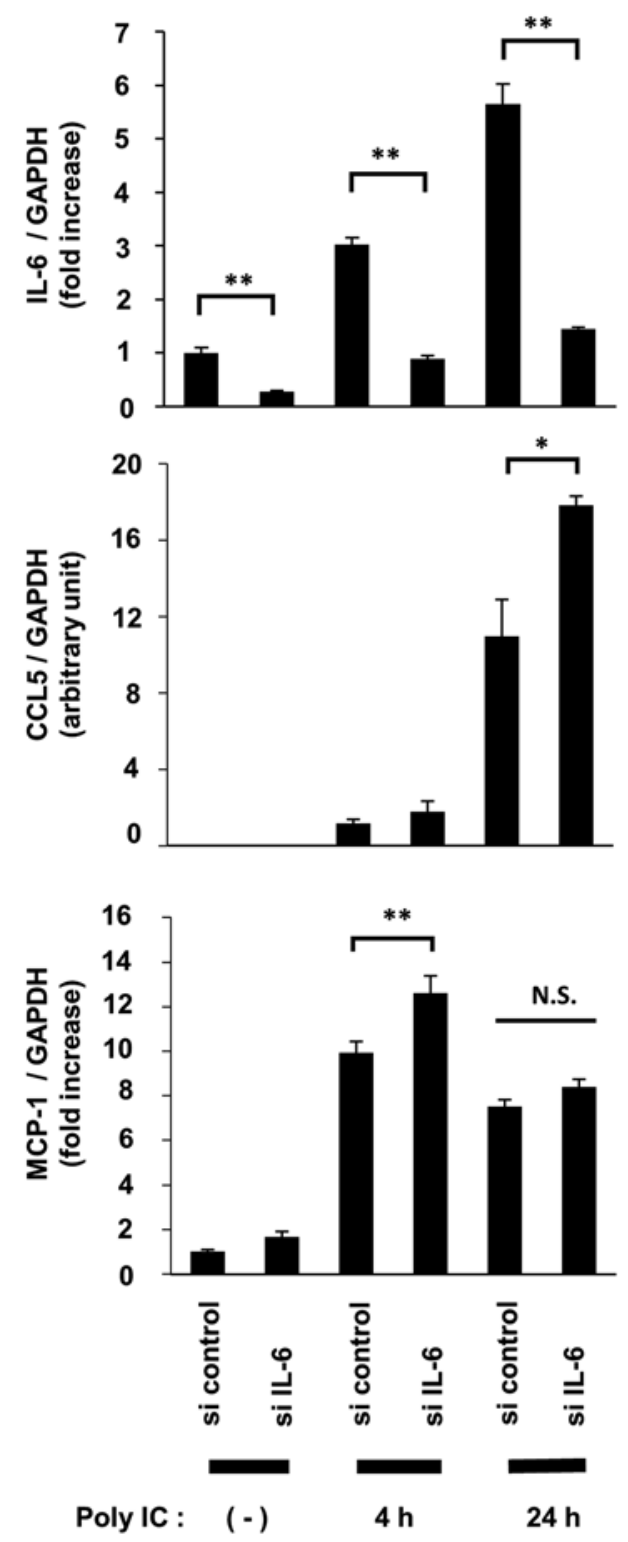

B. ELISA
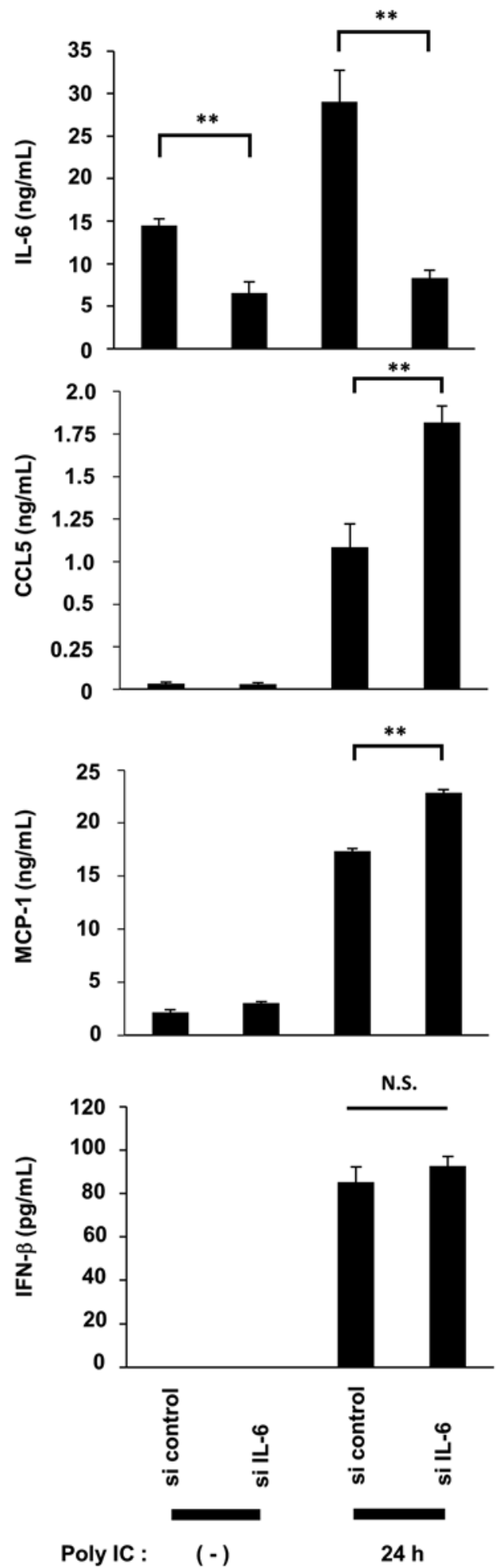

5

(For legend see next page.) 
hibited IL-6, CCL5, and MCP-1 mRNA (Fig. 4B) and protein (Fig. 4C) expression after 24 -h poly IC stimulation. The expression of MCP-1 mRNA was decreased by knockdown of IFN- $\beta$ significantly also after 4 -h poly IC stimulation.

\section{Knockdown of IL-6 Increases the Poly IC-Induced} Expression of MCP-1 and CCL5 in Cultured Human Podocytes

To examine the effect of poly IC-induced IL- 6 chemokine expression, we carried out siRNA targeting IL-6. Effective knockdown of IL- 6 by RNA interference was confirmed by qRT-PCR and ELISA. Knockdown of IL- 6 resulted in the significant increase of the expression of CCL5 mRNA (Fig. 5A) and protein (Fig. 5B). Knockdown of IL- 6 resulted in increased expression of MCP-1 mRNA after 4 -h poly IC treatment (Fig. 5A) and MCP-1 protein after $24 \mathrm{~h}$ poly IC treatment (Fig. 5B). However, knockdown of IL-6 had no effect on poly IC-induced increases in IFN- $\beta$ protein level.

r(h) IL-6 Decreases the Poly IC-Induced Expression of MCP-1 and CCL5 in Cultured Human Podocytes

To further examine the effect of IL- 6 on the expression of poly IC-induced chemokines, we next performed the treatment of cells with $\mathrm{r}(\mathrm{h})$ IL-6. Treatment of cells with $\mathrm{r}(\mathrm{h})$ IL- 6 attenuated the expression of CCL5 and MCP-1 mRNA (Fig. 6A) and protein (Fig. 6B) after 24 -h poly IC stimulation. The expression of MCP-1 mRNA was decreased significantly by 4 -h poly IC stimulation. $\mathrm{r}$ (h) IL-6 had no effect on poly IC-induced increase in IFN- $\beta$ protein level.

\section{Discussion}

IL-6 is a pleiotropic cytokine that regulates pro- and anti-inflammatory reactions in numerous cell types [15$17,20]$. In resident glomerular cells, IL- 6 can be produced by MCs, GECs, and podocytes and is involved in the pathogenesis of CKD $[11,17,20]$. Recently, we reported

Fig. 5. Knockdown of IL-6 increases the poly IC-induced expression of CCL5 and MCP-1 in cultured human podocytes. The cells were transfected with siRNA against IL- 6 or a nonsilencing negative control siRNA and incubated for $48 \mathrm{~h}$, before being stimulated with $10 \mu \mathrm{g} / \mathrm{mL}$ poly IC. A After an additional 4 or $24 \mathrm{~h}$ of incubation, RNA was extracted from the cells and was analyzed by qRTPCR. After an additional 24-h incubation, the conditioned medi- that the expression of IL- 6 is induced by activating TLR3 and its signaling pathway, which is tightly regulated in human GECs [11]; however, the specific mechanisms underlying the induction of IL-6 production via TLR3 signaling in human podocytes remain unknown. Thus, in the present study, we aimed to examine these mechanisms and found that poly IC treatment induced the expression of IL- 6 in human podocytes in a time- and concentration-dependent manner. Experiments using siRNA confirmed that this response was mediated by signaling via the TLR3/IFN- $\beta$ axis, which is consistent with the results of our previous studies using human MCs and GECs [4-11]. Concerning type I IFNs, our previous studies using cultured human MCs and GECs demonstrated that IFN- $\beta$, but not IFN- $\alpha$, synthesized de novo following TLR3 activation, is crucial in succeeding regional inflammatory cascades [3-12]. On the other hand, we found poly IC-stimulated expression of IFN- $\alpha$ in podocytes remained negative in our experimental setting. Recently, Migliorini et al. [21] reported that IFN- $\beta$ specifically promotes podocyte loss by inducing mitotic catastrophe of podocytes and both IFN- $\alpha$ and IFN- $\beta$ impair the differentiation of renal progenitors into mature podocytes. In the present study, protein levels of MCP-1 and CCL5 induced by poly IC were lesser owing to the increase in IL-6 (see Fig. 2B). Furthermore, knockdown of IL-6 significantly increased poly IC-induced MCP-1 and CCL5 in both messenger RNA and protein levels, thereby suggesting that TLR3 signaling-induced IL- 6 expression negatively regulates the expression of MCP-1 and CCL5 in human podocytes, although this theory remains speculative.

Considering the implication of toll/interleukin (IL)-1 receptor-domain-containing adapter-inducing interferon- $\beta$-dependent pathway-related TLR signaling in podocytes, the blockade of TLR4 signaling can prevent apoptosis in diabetic nephropathy mice models [22]. Shimada et al. [13] previously reported that activation of TLR3 signaling increased the expression of cathepsin L, decreased synaptopodin expression, and resulted in actin reorganization, leading to podocyte injury. In con- um was collected. B The concentration of IL-6, CCL5, MCP-1, and IFN- $\beta$ protein was measured by ELISA. C The expression of IL- 6 mRNA was measured by qRT-PCR to confirm the efficacy of siRNA against IL- 6 . The data are presented as means \pm SD $(n=3$, ns, nonsignificant, $\left.{ }^{*} p<0.05,{ }^{* *} p<0.01\right)$. Poly IC, polyinosinicpolycytidylic acid; IL-6, interleukin-6; CCL5, chemokine ligand 5; MCP-1, monocyte chemoattractant protein-1; IFN- $\beta$, interferon- $\beta$. 


\section{A. $q R T-P C R$}

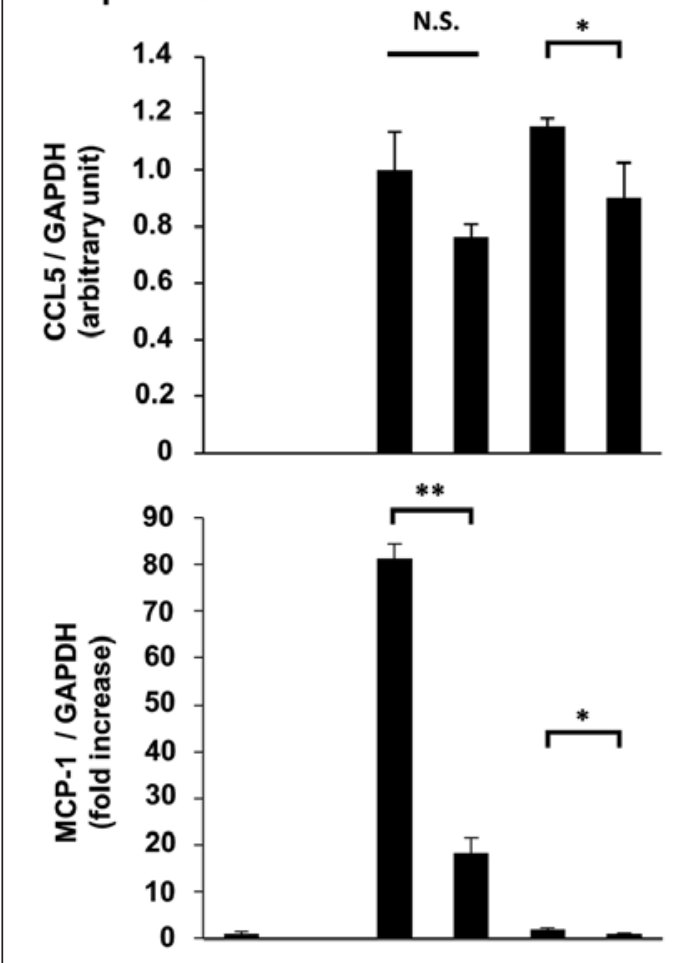

r(h) IL-6: (-) (+) (-) (+) (-) (+)

Poly IC :

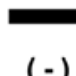

$(-)$

$$
4 \mathrm{~h}
$$

$24 \mathrm{~h}$

\section{B. ELISA}
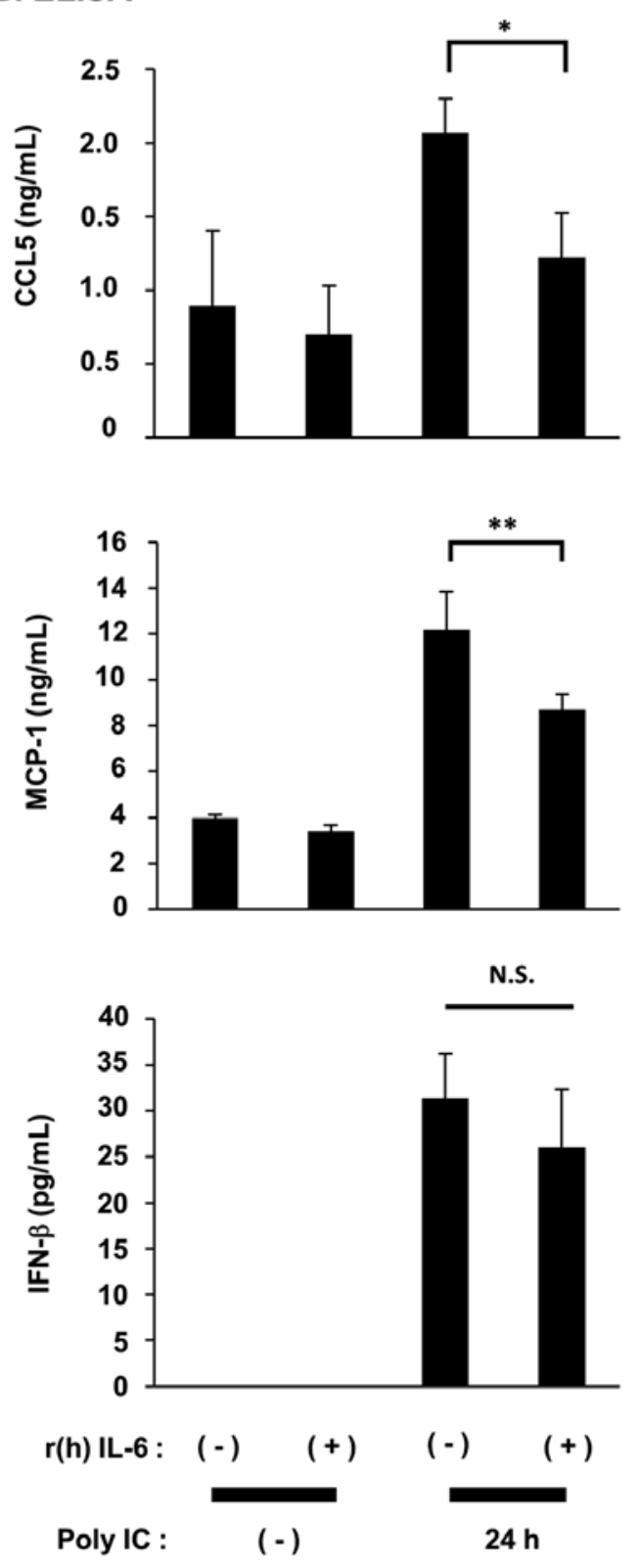

Fig. 6. Treatment of cells with r(h) IL-6 decreases the poly ICinduced expression of CCL5 and MCP-1 in cultured human podocytes. $\mathrm{r}(\mathrm{h}) \mathrm{IL}-6$ was added to cells at $40 \mathrm{ng} / \mathrm{mL}$, and cells were stimulated with $30 \mu \mathrm{g} / \mathrm{mL}$ poly IC. A After an additional $4 \mathrm{~h}$ or $24 \mathrm{~h}$ of incubation, RNA was extracted from the cells, and qRT-PCR analysis was performed. B After an additional $24 \mathrm{~h}$ of incubation, the conditioned medium was collected, and the con- centration of CCL5, MCP- 1 , or IFN- $\beta$ protein was measured by ELISA. The data are means $\pm \mathrm{SD}\left(n=3\right.$, ns, nonsignificant, ${ }^{*} p<$ $0.05,{ }^{* *} p<0.01$ ). Poly IC, polyinosinic-polycytidylic acid; IL-6, interleukin-6; CCL5, chemokine ligand 5; MCP-1, monocyte chemoattractant protein- 1 ; IFN- $\beta$, interferon- $\beta ; \mathrm{r}(\mathrm{h})$, recombinant human. 
trast, notably, TLR3 signaling has both protective and deleterious effects in the pathogenesis of viral infections [23]. Considering IL-6 in podocytes, it has been reported that high glucose exposure-induced IL- 6 expression is involved in the development of apoptosis of rat podocytes [18], whereas IL-6-dependent cellular crosstalk between podocytes and GECs may modulate glomerular inflammation via neutrophil recruitment [19]. Thus, once IL-6 appears via TLR3 signaling activation associated with viral infections in podocytes, this functional molecule may play a pivotal role in the glomerular inflammation.

Lee et al. [24] reported that in podocytes, transforming growth factor- $\beta$-induced MCP-1 expression enhances cellular mobility, rearranges actin cytoskeleton, and increases podocyte permeability to albumin, and these effects are blocked by a neutralizing anti-MCP-1 antibody. Moreover, it has been reported that MCP-1 and CCL5 cause podocyte injury by activating the tumor necrosis factor- $\alpha /$ nuclear factor- $\kappa \mathrm{B}$ pathway, which is postulated in the viral infection-induced system, and this system may be exaggerated by virus-induced nuclear factor- $\mathrm{kB}$ dysregulation [25]. Thus, attempts to improve the imbalance in expression levels of functional molecules, including MCP-1 and CCL5, may partly prevent podocyte injury in CKD. Therefore, further detailed studies on the implication of TLR3-induced IL-6 in podocytes are required to elucidate specific mechanism of CKD development or the exaggeration of pre-existing CKD following viral infections.

\section{Statement of Ethics}

This article does not contain any studies with human participants or animals performed by any of the authors which otherwise require ethical approval.

\section{Conflict of Interest Statement}

All the authors have declared no competing interest.

\section{Funding Sources}

This study was supported by Grants-in-Aid of the Japan Society for Promotion of Science (JSPS KAKENHI Grant No. 19K08338) to S.W. and a grant from Hirosaki University Institutional Research to H.T.

\section{Author Contributions}

S.W., T.I., and H.T. designed the study; H.U., T.I., T.A., S.W., and K.T. performed experiments; H.U. and H.T. wrote the manuscript; S.K., K.S., and T.M. gave technical support and conceptual advice. All authors read and approved the final manuscript.

\section{References}

1 Lai AS, Lai KN. Viral nephropathy. Nat Clin Pract Nephrol. 2006;2(5):254-62.

2 Bruggeman LA. Common mechanisms of viral injury to the kidney. Adv Chronic Kidney Dis. 2019;26(3): 164-70.

3 Kawai T, Akira S. TLR signaling. Cell Death Differ. 2006;13(5):816-25.

4 Robson MG. Toll-like receptors and renal disease. Nephron Exp Nephrol. 2009;113(1):e17.

5 Conti F, Spinelli FR, Truglia S, Miranda F, Alessandri C, Ceccarelli F, et al. Kidney expression of Toll-like receptors in lupus nephritis: quantification and clinicopathological correlations. Mediators Inflamm. 2016; 2016:7697592.

6 Tanaka H, Imaizumi T. Inflammatory chemokine expression via Toll-like receptor 3 signaling in normal human mesangial cells. Clin Dev Immunol. 2013;2013:984708.

7 Imaizumi T, Tanaka H, Matsumiya T, Yoshida H, Tanji K, Tsuruga K, et al. Retinoic acid- inducible gene-I is induced by double-stranded RNA and regulates the expression of CC chemokine ligand (CCL) 5 in human mesangial cells. Nephrol Dial Transplant. 2010; 25(11):3534-9.

8 Aizawa-Yashiro T, Imaizumi T, Tsuruga K, Watanabe S, Matsumiya T, Hayakari R, et al. Glomerular expression of fractalkine is induced by polyinosinic-polycytidylic acid in human mesangial cells: possible involvement of fractalkine after viral infection. Pediatr Res. 2013;73(2):180-6.

9 Imaizumi T, Aizawa T, Segawa C, Shimada M, Tsuruga K, Kawaguchi S, et al. Toll-like receptor 3 signaling contributes to the expression of a neutrophil chemoattractant, CXCL1 in human mesangial cells. Clin Exp Nephrol. 2015;19(5):761-70.

10 Liu Q, Imaizumi T, Kawaguchi S, Aizawa T, Matsumiya T, Watanabe S, et al. Toll-like receptor 3 signaling contributes to regional neutrophil recruitment in cultured human glomerular endothelial cells. Nephron. 2018; 139(4):349-58.

11 Liu Q, Imaizumi T, Aizawa T, Hirono K, Kawaguchi S, Watanabe S, et al. Cytosolic sensors of viral RNA are involved in the production of interleukin-6 via Toll-like receptor 3 signaling in human glomerular endothelial cells. Kidney Blood Press Res. 2019;44(1):6271.

12 Hirono K, Imaizumi T, Aizawa T, Watanabe S, Tsugawa K, Shiratori T, et al. Endothelial expression of fractalkine (CX3CL1) is induced by Toll-like receptor 3 signaling in cultured human glomerular endothelial cells. Mod Rheumatol. 2020;30(6):107481.

13 Shimada M, Ishimoto T, Lee PY, Lanaspa MA, Rivard CJ, Roncal-Jimenez CA, et al. Toll-like receptor 3 ligands induce CD80 expression in human podocytes via an NF-kBdependent pathway. Nephrol Dial Transplant. 2012;27(1):81-9. 
14 Yamashita $\mathrm{M}$, Millward CA, Inoshita $\mathrm{H}$, Saikia P, Chattopadhyay S, Sen GC, et al. Antiviral innate immunity disturbs podocyte cell function. J Innate Immun. 2013;5(3):231-41.

15 Scheller J, Chalaris A, Schmidt-Arras D, Rose-John S. The pro- and anti-inflammatory properties of the cytokine interleukin-6. Biochim Biophys Acta. 2011;1813(5):878-88.

16 Yang ML, Wang CT, Yang SJ, Leu CH, Chen $\mathrm{SH}, \mathrm{Wu} \mathrm{CL}$, et al. IL-6 ameliorates acute lung injury in influenza virus infection. Sci Rep. 2017;7:43829.

17 Su H, Lei CT, Zhang C. Interleukin-6 signaling pathway and its role in kidney disease: an update. Front Immunol. 2017;8:405

18 Kim DI, Park SH. Sequential signaling cascade of IL- 6 and PGC- $1 \alpha$ is involved in high glucose-induced podocyte loss and growth arrest. Biochem Biophys Res Commun. 2013; 435(4):702-7.
19 Kuravi SJ, McGettrick HM, Satchell SC, Saleem MA, Harper L, Williams JM, et al. Podocytes regulate neutrophil recruitment by glomerular endothelial cells via IL-6-mediated crosstalk. J Immunol. 2014;193(1):234-43.

20 Yung S, Cheung KF, Zhang Q, Chan TM. Mediators of inflammation and their effect on resident renal cells: implications in lupus nephritis. Clin Dev Immunol. 2013;2013: 317682.

21 Migliorini A, Angelotti ML, Mulay SR, Kulkarni OO, Demleitner J, Dietrich A, et al. The antiviral cytokines IFN- $\alpha$ and IFN- $\beta$ modulate parietal epithelial cells and promote podocyte loss: Implications for IFN toxicity, viral glomerulonephritis, and glomerular regeneration. Am J Pathol. 2013;183:431-40.
22 Saurus P, Kuusela S, Lehtonen E, Hyvönen ME, Ristola M, Fogarty CL, et al. Podocyte apoptosis is prevented by blocking the Tolllike receptor pathway. Cell Death Dis. 2015;6: e1752.

23 Patel MC, Shirey KA, Pletneva LM, Boukhvalova MS, Garzino-Demo A, Vogel SN, et al. Novel drugs targeting Toll-like receptors for antiviral therapy. Future Virol. 2014;9(9): 811-29.

24 Lee EY, Chung CH, Khoury CC, Yeo TK, Pyagay $\mathrm{PE}$, Wang $\mathrm{A}$, et al. The monocyte chemoattractant protein-1/CCR2 loop, inducible by TGF-beta, increases podocyte motility and albumin permeability. Am J Physiol Renal Physiol. 2009;297(1):F85-94.

25 Bruggeman LA, Drawz PE, Kahoud N, Lin K, Barisoni L, Nelson PJ. TNFR2 interposes the proliferative and NF- $\kappa \mathrm{B}$-mediated inflammatory response by podocytes to TNF- $\alpha$. Lab Invest. 2011;91(3):413-25. 